Sādhanā Vol. 38, Part 6, December 2013, pp. 1393-1405. (C) Indian Academy of Sciences

\title{
A temperature dependent slip factor based thermal model for friction stir welding of stainless steel
}

\author{
M SELVARAJ
}

Sri Sivasubramaniya Nadar College of Engineering, Chennai 603 110, India e-mail: selvarajm@ssn.edu.in

MS received 18 October 2012; revised 25 April 2013; accepted 3 May 2013

\begin{abstract}
This paper proposes a new slip factor based three-dimensional thermal model to predict the temperature distribution during friction stir welding of 304L stainless steel plates. The proposed model employs temperature and radius dependent heat source to study the thermal cycle, temperature distribution, power required, the effect of process parameters on heat generation per mm length of the weld and peak temperature during the friction stir welding process. Simulations of friction stir welding process were carried out on 304L stainless steel workpieces for various rotational and welding speeds. The predicted thermal cycle, power required and temperature distributions were found to be in good agreement with the experimental results. The heat generation per mm length of weld and peak temperature were found to be directly proportional to rotational speed and inversely proportional to welding speed. The rate of increase in heat generation per mm length of the weld and peak temperature are found to be higher at lower rotational speeds and lower at higher rotational speed. The heat generation during friction stir welding was found to be $80.8 \%$ at shoulder, $16.1 \%$ at pin side and $3.1 \%$ at the bottom of the pin.
\end{abstract}

Keywords. Friction stir welding; stainless steel; thermal model; temperature distribution and power.

\section{Introduction}

Friction stir welding (FSW) is a solid state joining process in which a specially designed nonconsumable rotating tool is used to weld the plates together. The tool employed in FSW has a larger diameter shoulder and a smaller diameter pin. The heat generated in friction stir welding process is primarily by friction between tool and workpiece and the plastic deformation of the workpiece material. The amount of heat generated is due to the friction and plastic deformation at the tool-workpiece interfaces that depends on tool geometry and welding parameters. The heat generated is conducted to both workpiece as well as the tool. The rate of heat transfer depends on the heat generation rate, conduction within the material and convection to the ambient. The temperature distribution across the workpiece depends on the amount of heat conducted into the plate. This in turn influences the material flow, microstructure, and mechanical properties 
of the weld zone (Lakshminarayanan et al 2009). To predict and control the temperature distribution during FSW process with reference to tool geometry, rotational and welding speed, it is necessary to carryout detailed thermal modelling of FSW.

The temperature distribution of FSW has been widely studied both experimentally and theoretically to understand both the welding process and welded materials. Dickerson et al (2003) presented a simple thermal model for FSW assuming a constant heat source to predict the heat flow into the tool and workpiece. A thermal model considering constant frictional heat at the tool shoulder and pin to predict the thermal history of aluminium alloy was developed by Rajamanickam et al (2009) and Riahi \& Nazari (2010). Song \& Kovacevic (2003) developed a thermal model of FSW process considering constant heat source at shoulder, pin side and bottom. The heat generation at shoulder due to friction alone and at pin due to friction and shearing are considered. Woo et al (2009) simulated the temperature distribution during FSW of aluminium alloy using the finite element software ABACUS considering constant frictional heat source. Chao \& Tang (2003) simulated a temperature distribution of FSW process using finite element software ABACUS considering radius dependent heat source. Prasanna et al (2010) presented a thermal model to predict the temperature distribution of FSW process of 304L stainless steel considering only frictional heat source as a function of radius. Nandan et al (2006) presented a three-dimensional heat and material flow model considering heat generation due to both friction and plastic deformation. In this model, a slip factor as a function of angular velocity of tool and radius is considered. Zhang et al (2011) presented a thermo-mechanical model of FSW process assuming a slip factor as a function of velocity difference between tool and workpiece material. Hamilton et al (2008) developed a thermal model of friction stir welding of aluminium alloy utilizing a slip factor based on the energy per unit length of weld. Three-dimensional thermal model for friction stir welding considering energy due to friction and plastic deformation is developed by Emam \& Domiaty (2009) assuming a refined energy based slip factor.

A review of literature on modelling of FSW process reveals that initially researchers have performed thermal modelling considering frictional heat source alone. Later made attempts on thermal modelling of FSW process by assuming the slip factor as a function of any one of the parameters such as (i) radius and angular velocity of tool, (ii) velocity difference between tool and workpiece material and (iii) energy per unit length of weld. The effect of temperature on slip factor has not been studied on thermal model of FSW. During the weld run, the heat generated by friction and shear deformation varies with temperature and thus the temperature effects on slip factor can not be neglected. In the present work, a three-dimensional transient thermal model with consideration of temperature effects on slip factor during FSW process of stainless steel has been proposed. A critical temperature of material flow (threshold) has been defined to predict the variation in slip factor with respect to temperature.

\section{Thermal model}

\subsection{Mathematical model}

At the beginning of the FSW process, the workpiece material is in a solid state and the tool slides over the workpiece material. Hence sliding condition is assumed at the tool-workpiece interface and heat is generated due to friction alone. The continuous operation causes a local heating and softens the workpiece material near the tool-workpiece interface. The partial sticking and sliding of material occurs (Schmidt et al 2004). When material sticks to the tool, plastic deformation of 
the material occurs at the interface. The expression for power required during FSW process is discussed below.

The power required during the FSW process is determined by considering both friction and shear deformation of the material (Hamilton et al 2009). The expressions for power required at contact surfaces such as shoulder, pin side and pin bottom are derived from the principle of solid mechanics (Durdanovic et al 2009).

The initial condition of the plate for calculation is given by

$$
T(x, y, z, t=0)=T_{a},
$$

where $T_{a}$ is the atmospheric temperature.

The convective boundary condition for all surfaces exposed to atmosphere is given by

$$
K \frac{\partial T}{\partial n}=h\left(T-T_{a}\right)
$$

where $h$ is the convective heat transfer coefficient at surfaces exposed to atmosphere and $n$ is the normal direction vector at boundary.

The heat flux boundary condition at the shoulder-workpiece interface is given by

$$
K \frac{\partial T}{\partial n}=-q_{s h}
$$

The heat flux boundary condition around the tool is given by

$$
K \frac{\partial T}{\partial n}=-q_{p i n}
$$

The temperature gradient along the transverse direction at the weld center line is negligible (Nandan et al 2006) and hence symmetry condition is assumed.

$$
\frac{\partial T}{\partial y}=0
$$

2.1a Power required at shoulder: Power required to overcome shoulder friction is given as

$$
P_{s h-f r}=\frac{2 \pi}{3} \mu p_{n} \omega\left(r_{s}^{3}-r_{p}^{3}\right) \text {. }
$$

$$
\text { Normal pressure, } p_{n}=\frac{F_{n}}{\pi r_{s}^{2}} \text {. }
$$

$$
\text { Angular velocity of tool, } \omega=\frac{2 \pi N}{60},
$$

where $\mu$ is the coefficient of friction, $r_{s}$ is the shoulder radius, $r_{p}$ is the pin radius, $F_{n}$ is the normal force and $N$ is the rotational speed of the tool. The subscript $s h-f r$ denotes shoulder friction. Buffa et al (2006) considered a constant coefficient of friction of 0.46 in their model. In this 
Table 1. FSW parameters.

\begin{tabular}{ll}
\hline Parameters & Value \\
\hline Shoulder diameter, $d_{s}$ & $19.5 \mathrm{~mm}$ \\
Pin diameter, $d_{p}$ & $6.35 \mathrm{~mm}$ \\
Pin height, $h$ & $3 \mathrm{~mm}$ \\
Normal load, $F_{n}$ & $31138 \mathrm{~N}$ \\
Rotational speeds, $N$ & 300,400 and $500 \mathrm{rpm}$ \\
Welding speeds, $V$ & 101,150 and $200 \mathrm{~mm} / \mathrm{min}$ \\
Workpiece dimensions & $150 \times 75 \times 3 \mathrm{~mm}$ \\
Density of workpiece, $\rho$ & $7800 \mathrm{~kg} / \mathrm{m}^{3}$ \\
\hline
\end{tabular}

model, the coefficient of friction is assumed to be linearly varying between 0.5 and 0.4 within the room and solidus temperature (Soundararajan et al 2005). Tool and welding parameters considered for stainless steel is shown in table 1.

Power required to cause shear deformation by the shoulder is given as

$$
\begin{gathered}
P_{s h-p l}=\frac{2 \pi}{3} \tau \omega\left(r_{s}^{3}-r_{p}^{3}\right) . \\
\text { Shear stress, } \tau=\frac{\sigma_{y}}{\sqrt{3}},
\end{gathered}
$$

where $\sigma_{y}$ is the temperature dependent yield stress of the workpiece material as shown in table 2 . The subscript $s h-p l$ denotes the shear deformation of shoulder.

The relationship between shear stress, viscosity and strain rate is described by Perzyna's viscoplasticity model (Nandan et al 2006) and is given as

$$
\text { Shear or flow stress, } \tau=3 \bar{\varepsilon} \mu \text {, }
$$

where $\bar{\varepsilon}=$ Strain rate and $\mu$ is viscosity of workpiece material.

Nandan et al (2006) stated that the material flow is significant when the viscosity is less than $4 \mathrm{MPa}-\mathrm{s}$ for the corresponding strain rate of $1.25 \mathrm{~s}^{-1}$. Substituting the values of viscosity and strain rate in Eq. (11), the corresponding shear stress is obtained as $15 \mathrm{MPa}$. This is called critical shear stress $\left(\tau_{c}\right)$. The temperature corresponding to the shear stress of $15 \mathrm{MPa}$ is about $1038^{\circ} \mathrm{C}$. This is known as critical temperature $\left(\mathrm{T}_{\mathrm{c}}\right)$ of material flow.

When temperature is less than the critical temperature, the material flow is negligible, hence perfect sliding condition is assumed and slip factor is one. In this condition, the contact shear stress is smaller than the material yield shear stress, hence the material shears slightly to a stationary elastic deformation (Schmidt et al 2004).

When temperature goes beyond the critical temperature, yield shear stress of material decreases and workpiece material becomes soft. In this condition, the contact shear stress is greater than the material yield shear stress, hence the material accelerates to a velocity less than the tool surface velocity where it stabilizes (Schmidt et al 2004). This leads to partial sliding and sticking condition.

At solidus temperature $\left(\mathrm{T}_{\mathrm{s}}\right)$, material shear stress is zero and material will accelerate along the tool surface and finally reaching the tool velocity (Schmidt et al 2004). Hence perfect sticking condition is assumed and slip factor is zero. 


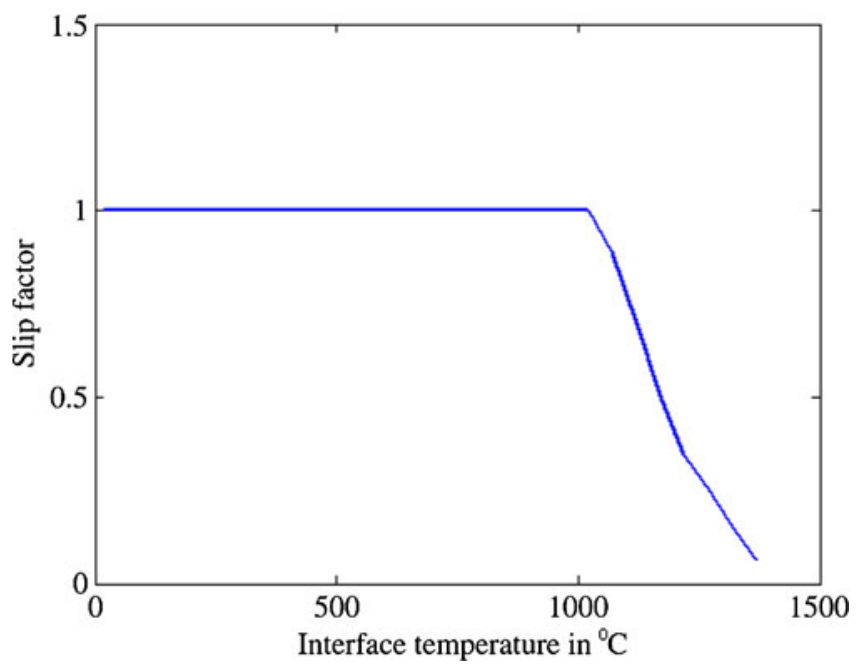

Figure 1. Slip factor as a function of interface temperature.

Slip factor is given by,

$$
\begin{array}{cc}
\delta=1 & \text { for } T_{a}<T<T_{c} . \\
\delta=\frac{\tau_{T}}{\tau_{c}} & \text { for } T_{s}>T>T_{c},
\end{array}
$$

where $\mathrm{T}_{\mathrm{a}}$ is room temperature, $\tau_{T}$ is shear stress of workpiece material at any temperature and $\tau_{c}$ is shear stress of workpiece material at critical temperature of material flow. The slip factor as a function of interface temperature is shown in figure 1.

Hence the expression for power required at the shoulder due to combined friction and shear deformation

$$
P_{s h}=(1-\delta) P_{s h-p l}+\delta P_{s h-f r}
$$

2.1b Power required at pin side: The normal force acting on the pin side is small compared to the normal force on the shoulder and pin bottom. For this reason, heat generation is removed from the model for simplification. Hence the power required to cause the plastic deformation alone is considered.

Power required at the pin side

$$
P_{p s-p l}=(1-\delta) 2 \pi \tau \omega r_{p}^{2} h,
$$

where $h$ is the height of the pin. The subscript $p s-p l$ denotes pin side shear deformation.

2.1c Power required at pin bottom: Power required to overcome pin bottom friction

$$
P_{p b-f r}=\frac{2 \pi}{3} \mu p_{n} \omega r_{p}^{3}
$$

The subscript $p b-f r$ denotes pin bottom friction. 
Power required to cause shear deformation by the pin bottom

$$
P_{p b-p l}=\frac{2 \pi}{3} \tau \omega r_{p}^{3}
$$

Power required at the pin bottom due to combined friction and shear deformation can be written as follows

$$
P_{p b}=(1-\delta) P_{p b-p l}+\delta P_{p b-f r}
$$

2.1d Total power required: Power required at the pin is given by,

$$
P_{p i n}=P_{p s}+P_{p b}
$$

Total power required, $P_{T}=P_{s h}+P_{p s}+P_{p b}$.

The parameters involved in power required (Eq. (1-19)) such as slip factor, shear stress and coefficient of friction are temperature dependent. Hence the power required during FSW process becomes a function of temperature.

2.1e Heat generation: It is assumed that all the power input to the tool in the FSW process is converted into heat (Mokhtar \& Victor 2010). Hence the heat generated at the shoulder, $Q_{s h}=$ $P_{s h}$, the heat generated at the pin, $Q_{\text {pin }}=P_{\text {pin }}$ and total heat generated, $Q_{T}=P_{T}$. The heat generation per mm length of weld is given as

$$
Q_{l}=\frac{Q_{T}}{V} \times 60
$$

It is assumed that $75 \%$ of total heat generated during FSW is transferred to workpiece and remaining to tool which is also reported by Chao et al (2003). The heat generated in the shoulder is assumed to be linearly proportional to the distance from the axis of the tool (Schmidt et al 2004). Hence the heat flux at the shoulder becomes a function of radius. Then the expression for heat flux transmitted to workpiece at the shoulder-workpiece interface at any radius, $r$

$$
q_{s h}=0.75 \times \frac{3 Q_{s h} r}{2 \pi\left(r_{s}^{3}-r_{p}^{3}\right)} \quad \text { for } \quad r_{p} \leq r \leq r_{s} .
$$

The heat generation for the pin at the side and bottom are considered. However, the major heat source in the pin is due to the pin side surface (Schmidt et al 2004). Hence the heat generated by the pin is applied as a volume heat flux around the pin in the shape of hollow cylinder. Chen et al (2008) stated that the shear zone around the pin is characterized by the total disappearance of the original rolled structure of the workpiece material. It is approximately varying from $0.5 \mathrm{~mm}$ at the advancing side to $4 \mathrm{~mm}$ at the retreating side. The average size of shear zone of $2 \mathrm{~mm}$ is taken in this model. The outer diameter, inner diameter and height of volume heat flux are $r_{p}+2$, $r_{p}$ and $h \mathrm{~mm}$ respectively and volume heat flux transmitted to workpiece at the pin-workpiece interface

$$
q_{\text {pin }}=0.75 \times \frac{Q_{\text {pin }}}{\pi\left[\left(r_{p}+2\right)^{2}-r_{p}^{2}\right] h} .
$$


Table 2. Properties of 304 L stainless steel (Chao \& Tang 2003).

\begin{tabular}{|c|c|c|c|c|c|c|}
\hline Temperature in ${ }^{\circ} \mathrm{C}$ & 30 & 200 & 400 & 600 & 800 & 1000 \\
\hline Yield stress in $\mathrm{MPa}$ & 290 & 235 & 200 & 170 & 42 & 30 \\
\hline Conductivity in $\mathrm{W} / \mathrm{m}^{\circ} \mathrm{C}$ & 16 & 19 & 21 & 24 & 29 & 30 \\
\hline Specific heat in $\mathrm{J} / \mathrm{kg}^{\circ} \mathrm{C}$ & 500 & 540 & 560 & 590 & 600 & 610 \\
\hline
\end{tabular}

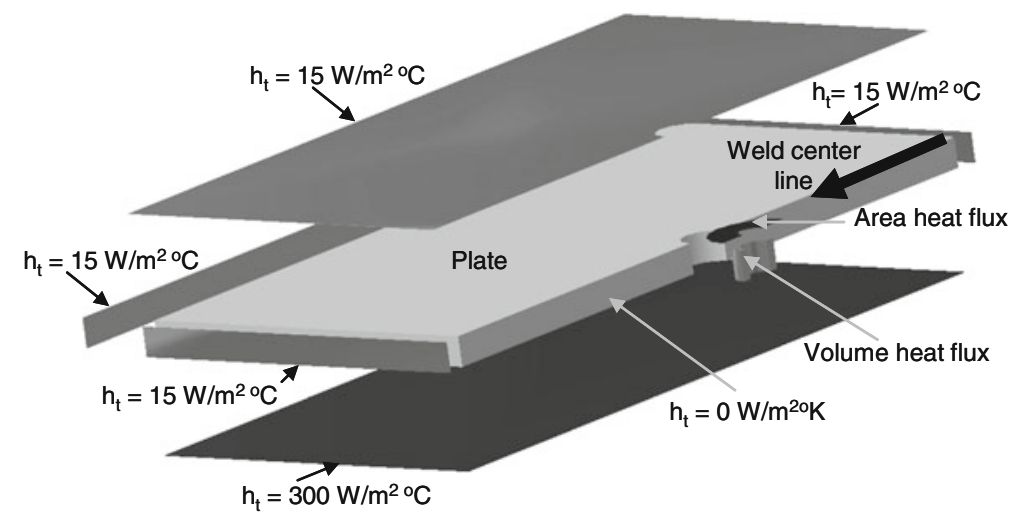

Figure 2. Exploded view of the model with heat fluxes and boundary conditions.

The slip factor, shear stress, and coefficient of friction used in the heat flux calculation (Eq. (1-22)) are temperature dependent. The heat flux at the shoulder depends on temperature and shoulder radius whereas the volume heat flux around the pin depends on temperature alone.

\subsection{Finite element model}

In this work, ANSYS software was used for the transient thermal analysis of FSW process. Half portion of the welded plate with respect to the weld center line is modelled due to symmetry. The temperature dependent thermal conductivity and specific heat capacity of $304 \mathrm{~L}$ stainless steel considered are shown in table 2.

Three dimensional eight-noded solid 70 brick element is employed in this analysis. The heat source was moved in discrete steps of $1 \mathrm{~mm}$ to simulate the linear motion of the tool. At each load step, a set of nodes at the tool-workpiece interface was selected and heat fluxes were applied. The heat generated at shoulder is applied as temperature and radius dependent heat flux on nodes at the shoulder-workpiece interface. The heat generated by the pin was applied as temperature dependent volume heat flux on nodes around the pin-workpiece interface as shown in figure 2.

Initially, temperature of the workpiece is assumed to be at ambient temperature of $30^{\circ} \mathrm{C}$. The simulation was conducted for three welding speeds of 101, 150 and $200 \mathrm{~mm} / \mathrm{min}$. Each with three rotational speeds of 300, 400 and $500 \mathrm{rpm}$ and total nine simulations were performed.

\section{Results and discussion}

\subsection{Thermal cycle}

Figures $3 \mathrm{a}$ and $\mathrm{b}$ show the comparison of numerical results of the present work with that of experimental results of Zhu \& Chao (2004) on thermal cycle at specified locations from the weld 

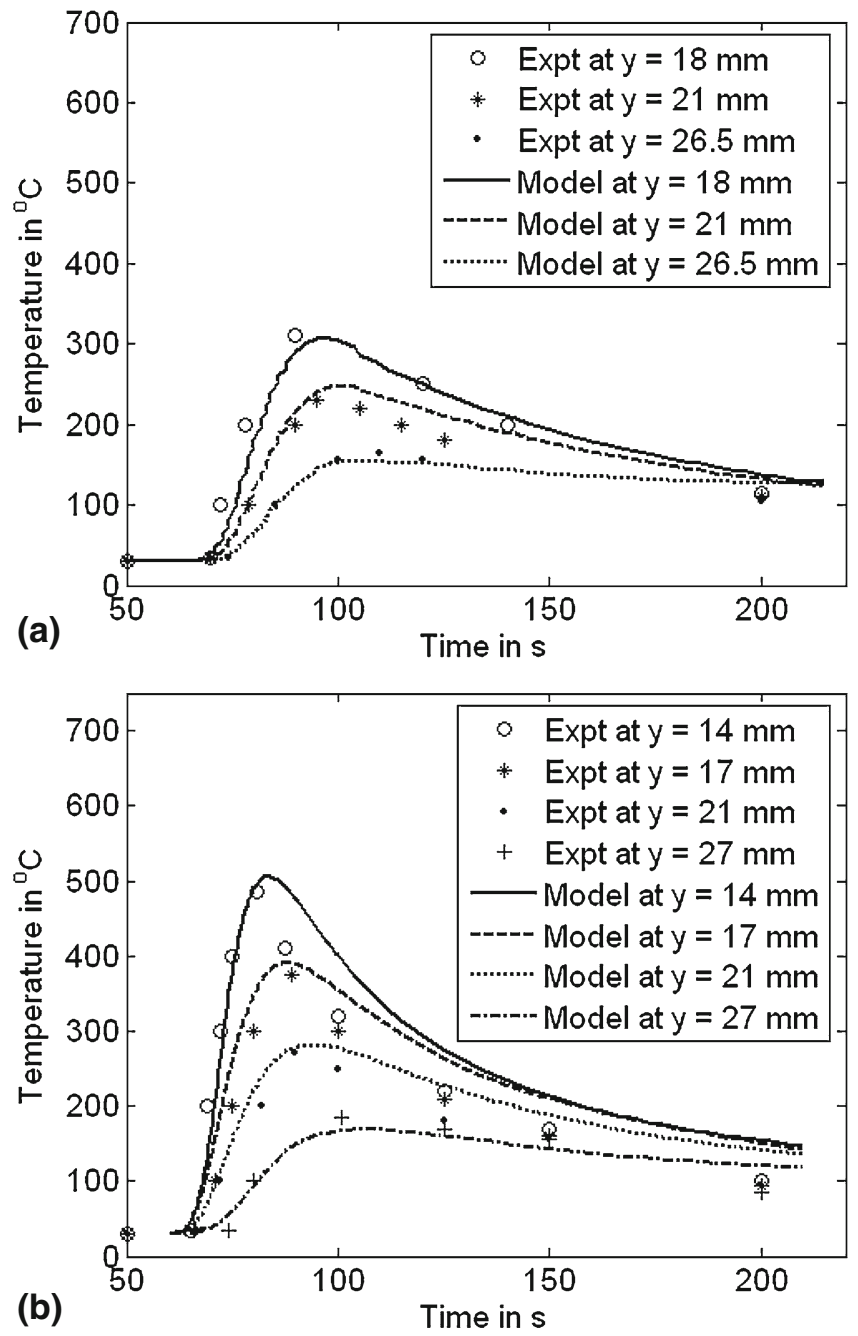

Figure 3. (a) Simulated thermal cycle with experimental data (Zhu \& Chao 2004) for welding speed of $101 \mathrm{~mm} / \mathrm{min}$ and rotational speed of $300 \mathrm{rpm}$. (b) Simulated thermal cycle with experimental data (Zhu \& Chao 2004) for welding speed of $101 \mathrm{~mm} / \mathrm{min}$ a rotational speed of $500 \mathrm{rpm}$.

center line for two different rotational speeds of 300 and $500 \mathrm{rpm}$, respectively. The predicted thermal cycle shows good agreement with the magnitude and shape of the experimental cycle.

\subsection{Temperature distribution along transverse distance}

Figure 4a compares the simulated peak temperature with experimental results of Zhu \& Chao (2004) along the transverse distance for two rotational speeds of 300, and $500 \mathrm{rpm}$. The peak temperature is the maximum temperature experienced by the workpiece during welding at the specific location. It is observed that simulated temperature profile and experimental profile are closely matching. 


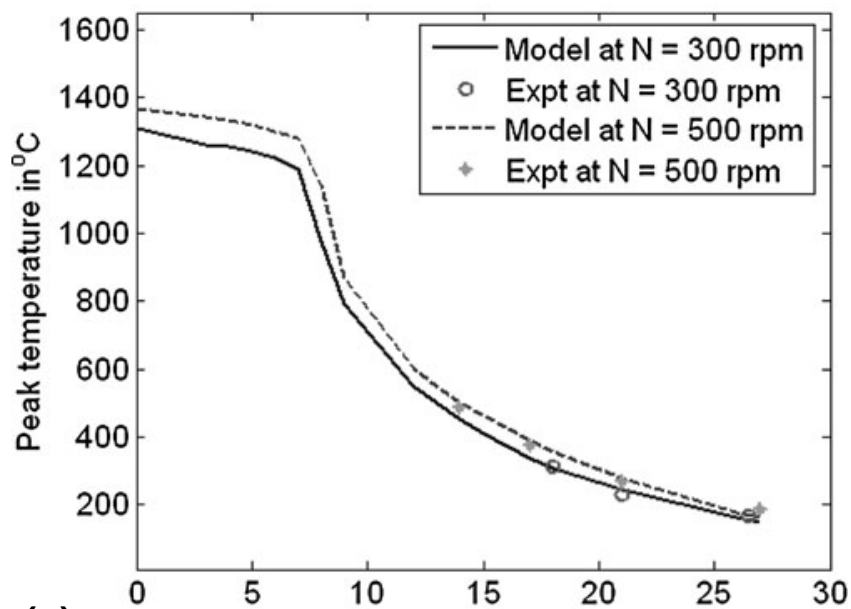

(a) Distance perpendicular to weld center line in $\mathrm{mm}$

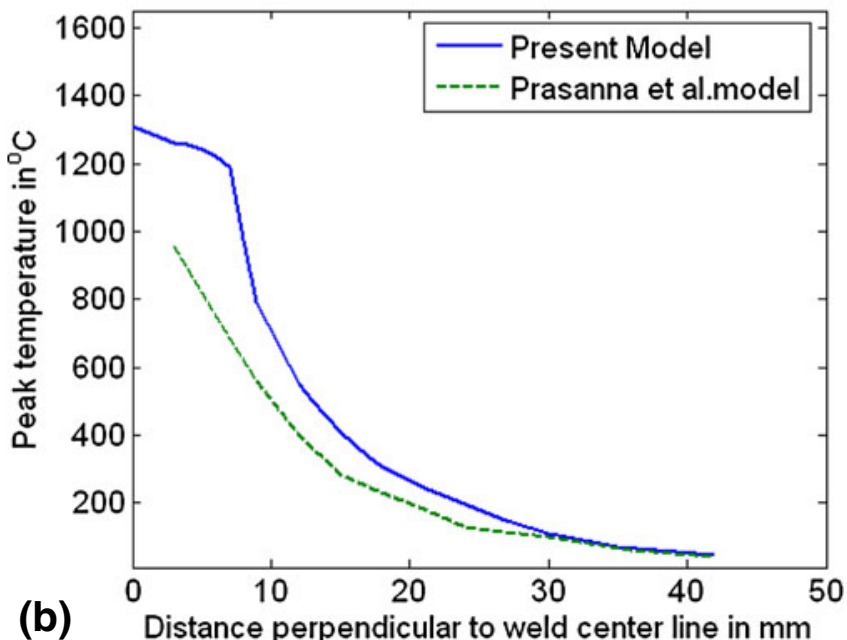

Figure 4. (a) Simulated peak temperature with experimental data (Zhu \& Chao 2004) along the transverse direction from the weld center line. (b) Comparison of peak temperature distribution of present model with Prasanna et al (2010) model for welding speed of $101 \mathrm{~mm} / \mathrm{min}$ and rotational speed of $300 \mathrm{rpm}$.

A comparison of peak temperature distribution predicted by the present model with Prasanna et al (2010) model for welding speed of $101 \mathrm{~mm} / \mathrm{min}$ and rotational speed of $300 \mathrm{rpm}$ is given in figure 4b. Prasanna et al (2010) developed a thermal model to predict the temperature distribution of FSW process of $304 \mathrm{~L}$ stainless steel considering only frictional heat source as a function of radius. Figure $4 \mathrm{~b}$ shows that the present model over predicts the peak temperatures under the shoulder and matches closely beyond the shoulder. In general, the temperature distribution in friction stir welding under the shoulder will be almost flat due to the presence of heat source (heat generation due to shoulder) and then there is sudden drop in temperature at the shoulder edge. This general trend in friction stir welding is followed in the temperature distribution predicted by the present model. 


\subsection{Power required}

The power required during FSW process is determined from the Eq. (1-19). The parameters involved in power calculation such as slip factor, shear stress and coefficient of friction are temperature dependent. Hence the power required during FSW process is a function of toolworkpiece interface temperature. But the temperature across the interface is not constant. Hence the power is determined based on the mean temperature of tool-workpiece interface. The mean temperature at the tool-workpiece interface for constant welding speed of $101 \mathrm{~mm} / \mathrm{min}$ and rotational speed of 300 and $500 \mathrm{rpm}$ are 1170 and $1225^{\circ} \mathrm{C}$. And the power corresponding to the mean temperatures are estimated as 1808 and $2104 \mathrm{~W}$, respectively. The experimentally measured powers are 1760 and $2240 \mathrm{~W}$, respectively (Zhu \& Chao 2004). The variation between the experimental and numerical power are $2.7 \%$ and $6 \%$, respectively. The experimentally measured power matches well with the power determined by model.

\subsection{Effect of welding and rotational speed on heat generation}

The mean temperature for the welding speed of $101 \mathrm{~mm} / \mathrm{min}$ and rotational speed of $300 \mathrm{rpm}$ is $1170^{\circ} \mathrm{C}$. And the power or heat generation corresponding to the mean temperature at the shoulder pin side and pin bottom are 1460, 292, $56 \mathrm{~W}$ respectively. The heat generation at the shoulder, pin side and pin bottom are $80.8 \%, 16.1 \%$ and $3.1 \%$, respectively. The heat generation at shoulder is high due to the higher contact area and radius of rotation. Similar trend is found for the other parameters also.

The heat generation per mm length of weld as a function of rotational speeds for welding speeds 101,150 and $200 \mathrm{~mm} / \mathrm{min}$ is illustrated in figure 5. It is observed that the heat generation per mm length of weld is directly proportional to rotational speed. When rotational speed increases, the heat generation per mm length of weld increases due to the higher rubbing velocity at the tool-workpiece interface. It is also observed that the slope of the curve is greater at lower rotational speeds than higher rotational speeds. For example, when rotational speed changes

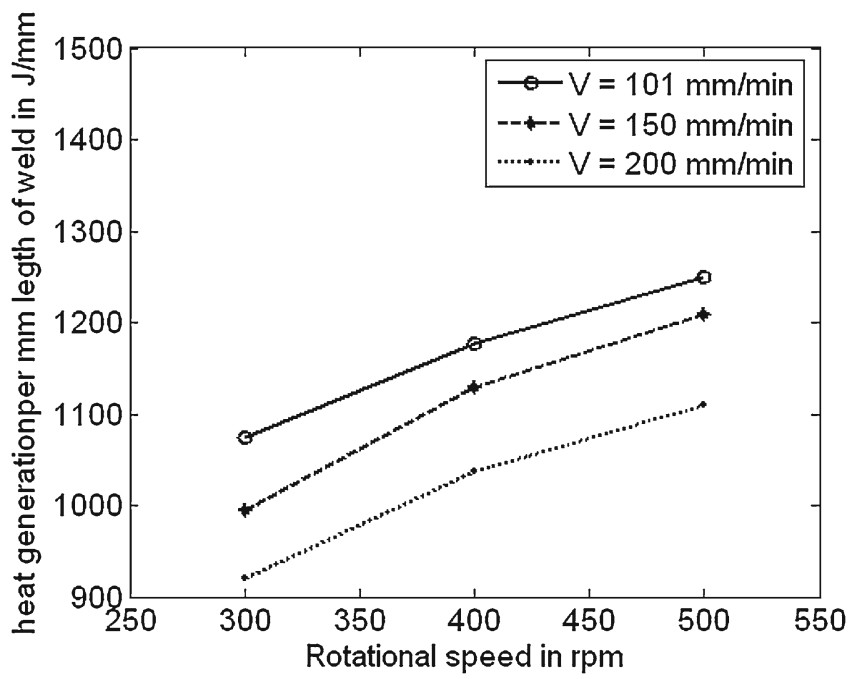

Figure 5. Heat generation per mm length of weld as a function of rotational speed for welding speeds of 101,150 and $200 \mathrm{~mm} / \mathrm{min}$. 
from 300 to $400 \mathrm{rpm}$ for a welding speed of $101 \mathrm{~mm} / \mathrm{min}$, the increase in heat generation per $\mathrm{mm}$ length of weld is $103 \mathrm{~J} / \mathrm{mm}$, whereas when rotational speed changes from 400 to $500 \mathrm{rpm}$, the increase in heat generation per mm length of weld is $73 \mathrm{~J} / \mathrm{mm}$. This indicates that the rate of increase in heat generation per mm length of weld decreases as rotational speed increases. It is also observed that the heat generation per mm length of weld is inversely proportional to the welding speed. When welding speed increases, the heat generation per mm length of weld decreases due to the lesser welding time.

\subsection{Effect of rotational and welding speed on peak temperature}

The simulated peak temperature at the weld center line as a function of rotational speeds for welding speeds 101,150 and $200 \mathrm{~mm} / \mathrm{min}$ is illustrated in figure 5. It is observed that the peak temperature is directly proportional to rotational speed. It is also observed that the slope of the curve is greater at lower rotational speeds than higher rotational speeds. For example, when rotational speed changes from 300 to $400 \mathrm{rpm}$ for a welding speed of $101 \mathrm{~mm} / \mathrm{min}$, the increase in peak temperature is $38^{\circ} \mathrm{C}$, whereas when rotational speed changes from 400 to $500 \mathrm{rpm}$, the increase in peak temperature is $21^{\circ} \mathrm{C}$. As rotational speed increases further, rate of increase in heat generation per mm length and temperature decreases and finally reaches the steady state. This state will restrict the maximum temperature within the melting point of the material. Practically the maximum temperature during friction stir welding can not go beyond melting point of the material. This condition is achieved because of the use of temperature dependent slip factor which governs the fraction of heat generated by friction and plastic deformation. This indicates that the rate of increase in peak temperature decreases as rotational speed increases. The rate of increase in heat generation per mm length of weld also follow the same trend as peak temperature when rotational speed increases as shown in figure 6. Hence it is clear that the peak temperature depends on the heat generation per mm length of weld. It is also observed that the peak temperature is inversely proportional to welding speed. When welding velocity increases, the heat generation per mm length of weld decreases (figure 5) and in turn peak temperature decreases.

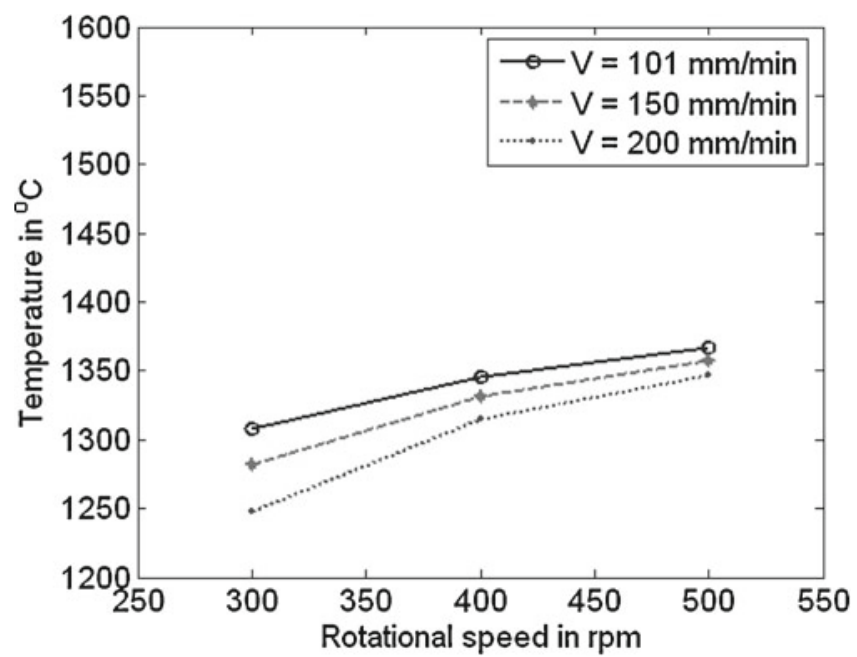

Figure 6. Simulated peak temperature at the weld center line as a function of rotational speed for welding speeds of 101,150 and $200 \mathrm{~mm} / \mathrm{min}$. 


\section{Conclusions}

(i) A temperature dependent slip factor based three-dimensional thermal model for friction stir welding is developed with capability of predicting thermal cycle, temperature distribution, power required and heat generated per unit length for friction stir welding of stainless steel.

(ii) The simulated temperature cycles at specified locations from the weld centerline and temperature distribution along the transverse direction are in good agreement with that of experimental results.

(iii) The calculated power matches well with experimentally measured power.

(iv) The heat generation per mm length of weld is directly proportional to rotational speed and inversely proportional to the welding speed. The rate of increase in heat generation per $\mathrm{mm}$ length of weld decreases as rotational speed increases.

(v) The peak temperature is directly proportional to rotational speed and inversely proportional to welding speed. The effect of rotational speed on peak temperature shows that rate of increase in peak temperature decreases as rotational speed increases.

(vi) The heat generation due to shoulder, pin side and pin bottom calculated based on the model are $80.8 \%, 16.1 \%$ and $3.1 \%$, respectively.

\section{References}

Buffa G, Hua J, Shivpuri R and Fratini L 2006 A continuum based fem model for friction stir weldingmodel development. Mater. Sci. Eng. A 419: 389-398

Chao Y J, Qi X and Tang W 2003 Heat transfer in friction stir welding-experimental and numerical studies. ASME J. Manuf. Sci. Eng. 125: 138-145

Chao Y J and Tang W 2003 Heat transfer in friction stir welding-experimental and numerical studies. Trans. ASME 125: 138-145

Chen Z, Pasang T and Qi Y 2008 Shear flow and formation of Nugget zone during friction stir welding of aluminium alloy 5083-O. Mater. Sci. Eng. A 474: 312-316

Dickerson T, Shi Q and Shercliff H R 2003 Heat flow into friction stir welding tools, $4^{\text {th }}$ International Symposium on Friction Stir Welding, Park City, Utah, 14-16

Durdanovic M B, Mijajlovic M M, Milcic D S and Stamenkovic D S 2009 Heat generation during friction stir welding process. Tribology in Industry 31: 11-21

Emam S A and Domiaty A E 2009 A refined energy-based model for friction-stir welding. World Academy of Sci. Eng. Technol. 53: 1016-1022

Hamilton C, Dymek S and Sommers A 2008 A thermal model of friction stir welding in aluminum alloys. Int. J. Machine Tools \& Manuf. 48: 1120-1130

Hamilton C, Sommers A and Dymek S 2009 A thermal model of friction stir welding applied to Sc-modified $\mathrm{Al}-\mathrm{Zn}-\mathrm{Mg}-\mathrm{Cu}$ alloy extrusions. Int. J. Machine Tools \& Manuf. 49: 230-238

Lakshminarayanan A K, Balasubramanian V and Elangovan K 2009 Effect of welding processes on tensile properties of AA6061 aluminium alloy joints. Int. J. Advanced Manuf. Technol. 40: 286-296

Mokhtar A and Victor H M 2010 Energy generation during friction stir spot welding (FSSW) of Al 6061-T6 plates. Mater. Manuf. Processes 25: 167-174

Nandan R, Roy G G, Lienert T J and DebRoy T 2006 Numerical modelling of 3D plastic flow and heat transfer during friction stir welding of stainless steel. Sci. Technol. Welding and Joining 11: 526-537

Prasanna P, Rao B S and Mohana Rao G K 2010 Finite element modelling for maximum temperature in friction stir welding and its validation. Int. J. Advanced Manuf. Technol. 51: 925-933

Rajamanickam N, Balusamy V, Reddy G M and Natarajan K 2009 Effect of process parameters on thermal history and mechanical properties of friction stir welds. Mater. Design 30: 2726-2731 
Riahi M and Nazari H 2010 Analysis of transient temperature and residual thermal stresses in friction stir welding of aluminum alloy 6061-T6 via numerical simulation. Int. J. Advanced Manuf. Technol. 55: $143-152$

Schmidt H, Hattel J and Wert J 2004 An analytical model for heat generation in friction stir welding. Modelling simul. Mater. Sci. Eng. 12: 143-157

Song M and Kovacevic R 2003 Thermal modelling of friction stir welding in a moving coordinate system and its validation. Int. J. Machine Tools \& Manuf. 43: 605-615

Soundararajan V, Zekovic S and Kovacevic R 2005 Thermo-mechanical model with adaptive boundary conditions for friction stir welding of Al 6061. Int. J. Machine Tools \& Manuf. 45: 1577-1587

Woo W, Choo H, Withers P J and Feng Z 2009 Prediction of hardness minimum locations during natural aging in an aluminum alloy 6061-T6 friction stir weld. J. Mater. Sci. 44: 6302-6309

Zhang Z, Chen J T, Zhang Z W and Zhang H W 2011 Coupled thermo-mechanical model based comparison of friction stir welding processes of AA2024-T3 in different thicknesses. J. Mater. Sci. 46: 5815-5821

Zhu X K and Chao Y J 2004 Numerical simulation of transient temperature and residual stresses in friction stir welding of 304L stainless steel. J. Mater. Processing Technol. 146: 263-272 